\title{
PRÁTICAS DE GESTÃO AMBIENTAL EM UNIVERSIDADES BRASILEIRAS
}

\author{
Raquel Engelman Machado \\ Professora Do Instituto de Ciências Sociais Aplicadas pela Universidade Feevale \\ raquelengelman@hotmail.com
}

Edi Madalena Fracasso

Professora do Programa de Pós-Graduação pela Universidade Federal do Rio Grande do Sul

Patricia Tometich

Doutoranda em Administração pela Universidade Federal do Rio Grande do Sul ptometich@gmail.com

\section{Luis Felipe Nascimento}

Professor do Programa de Pós Graduação pela Universidade Federal do Rio Grande do Sul nascimentolf@gmail.com

\section{RESUMO}

As Universidades devem cumprir seu papel de educação e pesquisa e servir de exemplo por meio de suas práticas de Gestão Ambiental, minimizando impactos, ao mesmo tempo em que contribuem com a conscientização da sociedade. Assim, este trabalho teve como objetivo identificar práticas de Gestão Ambiental realizadas nas Universidades brasileiras tendo como base um survey com 75 instituições. Este estudo evidenciou que 22 práticas são realizadas por grande parte das Universidades do país. Instituições que priorizam a Gestão Ambiental, implantando SGA e departamento específico para sua gestão, apresentam nível mais elevado de adoção de práticas. As principais motivações estão relacionadas com a preocupação em relação ao meio ambiente e em conscientizar a sociedade por meio de projetos de educação/servindo como exemplo. Este resultado demonstra que, apesar das dificuldades, as instituições brasileiras estão voltadas a cumprir com sua responsabilidade ambiental e social. Em relação às principais barreiras foram apontadas a falta de recursos, principalmente humanos e financeiros, dificuldade de conscientização dos envolvidos e falta de interesse das próprias IESs. É importante que Universidades contem com apoio governamental adequado às suas características, que organizem programas internos de conscientização de servidores, que políticas ambientais sejam prioridade para a gestão das instituições, fazendo parte de seu planejamento estratégico e de sua previsão orçamentária.

Palavras-chave: Gestão ambiental; Práticas; Responsabilidade social; Universidades.

\section{ENVIRONMENTAL MANAGEMENT PRACTICES IN BRAZILIAN UNIVERSITIES}

\begin{abstract}
Universities must fulfill education and research roles and serve as an example in terms of their environmental management practices, minimizing impacts while contributing to the awareness of society. This study aims to identify Environmental Management practices in Brazilian universities from a survey of 75 institutions. The study shows that 22 practices are carried out by most of the Universities in the country. Institutions that prioritize environmental management, implementing EMS and deploying specific departments for their management have higher levels of practices adoption. The main motivations are related to concerns in relation to the environment and society awareness through education projects and serving as an example. This result demonstrates that despite the difficulties, Brazilian institutions are directed to comply with its environmental and social responsibilities. Lack of resources, particularly human and financial, awareness of the difficulty involved and lack of the own IES interest were the main barriers found. It is important that universities count on government support suited to their characteristics, and that they organize internal servers' awareness programs and that environmental policies are institution managements' priorities to enact strategic planning and budget forecasting.
\end{abstract}

Key words: Environment management; Practices; Social responsibility; Universities. 


\section{INTRODUÇÃO}

A emergência dos problemas ambientais e das suas implicações econômicas e sociais no comprometimento do futuro nas sociedades modernas fez com que se considerasse a via do desenvolvimento sustentável como alternativa às abordagens tradicionais dos problemas de desenvolvimento. Neste contexto, as Universidades são tanto parte do problema, pois também são organizações que utilizam recursos do meio ambiente, quanto parte da solução, pois detêm a capacidade e responsabilidade de adotar a sustentabilidade nas suas políticas e práticas de gestão, influenciando o presente e o futuro das sociedades, por meio da transmissão de conhecimento, além de servir como exemplo de comportamento social e ambientalmente responsável.

Para Salgado (2006), as Instituições de Ensino Superior (IESs) são um importante veículo para a disseminação da conscientização necessária, por meio da educação e da pesquisa de novas práticas e tecnologias. As IESs são agentes de desenvolvimento social, qualificando e conscientizando os formadores de opinião (Kraemer, 2004). Assim, a revolução em prol da sustentabilidade traz consigo a importância da adoção de ações relacionadas ao desenvolvimento sustentável em todas as suas frentes de atuação.

Segundo Fouto (2002), o papel da Universidade na sociedade tem como base três frentes de atuação: (a) a educação, (b) a pesquisa e (c) a operação dos campi universitários. Neste sentido, as Instituições de Ensino Superior, além do papel educativo e de pesquisa, devem ser modelos das iniciativas de sustentabilidade em escala local, pois os exemplos de boas práticas nos seus próprios campi auxiliam a conscientização e o ensino de seus alunos, que possuem papel multiplicador (Kraemer, 2004, Engelman; Guisso; Fracasso, 2009).

As IESs precisam praticar aquilo que ensinam e a minimização dos impactos ambientais nas Universidades, por meio de Sistemas de Gestão Ambiental, é parte da solução para a sustentabilidade dos campi universitários (Careto; Vendeirinho, 2003). Para Tauchen e Brandli (2006), as IESs se assemelham aos núcleos urbanos devido às suas instalações onde se desenvolvem atividades variadas (ensino, alimentação, hospitais, centros de convivência, etc.), o que requer grande esforço de Gestão Ambiental. A Gestão Ambiental pode ser definida como um conjunto de procedimentos para gerir ou administrar uma organização na sua interface com o meio ambiente, é a forma pela qual a organização se mobiliza, interna e externamente, para a conquista da qualidade ambiental desejada (Donaire, 1999; Maimon, 1999).

Em várias partes do mundo, principalmente nos países desenvolvidos, as ações das IESs em relação à sustentabilidade estão crescendo. De acordo com Tilbury, presidente do grupo de especialistas em avaliação de educação para o desenvolvimento sustentável da Unesco, entre 2007 e 2010, houve um aumento de $15 \%$ de Universidades que firmaram cartas e declarações neste sentido, e um aumento de $6 \%$ na oferta de cursos voltados ao desenvolvimento sustentável. Na Inglaterra, houve um aumento de $82 \%$ das Universidades que desenvolveram estratégias para a redução da emissão de carbono e 53\% que adotaram critérios verdes nas suas compras (Tilbury, 2012). Entretanto, não foi identificado, na literatura sobre o tema, um estudo que descrevesse o comportamento do conjunto das IESs brasileiras no que diz respeito às políticas e ações voltadas à sua própria sustentabilidade. Este trabalho tem então como objetivo identificar as práticas de Gestão Ambiental realizadas nas Universidades brasileiras.

Para atender ao propósito desta pesquisa, além desta introdução, a segunda seção traz o histórico do desenvolvimento da Gestão Ambiental nas Instituições de Ensino Superior e das principais ações identificadas na ISO 14001 e em estudos sobre IES, tanto no Brasil, quanto no mundo. Na terceira seção, é descrito o método referente à pesquisa tipo survey realizada com 75 Universidades brasileiras. Seguem-se as seções de análise dos resultados e a conclusão.

\section{GESTÃO AMBIENTAL EM UNIVERSIDADES}

Considerando sua importância na conscientização da sociedade na adoção de práticas mais sustentáveis, a partir da década de 1960, as Instituições de Ensino Superior começaram a introduzir em seus sistemas de gestão algumas ações ambientais. Com a Conferência de Estocolmo, em 1972,

Revista de Gestão Social e Ambiental - RGSA, São Paulo, v. 7, n. 3, p. 37-51, out./dez., 2013. 
emergiram diversas parcerias e redes de trabalho, bem como instituições de ensino voltadas a trazer a discussão sobre o desenvolvimento sustentável para o âmbito das IESs. Na década de 1980, essas iniciativas foram aumentando tanto em importância, quanto em número, priorizando a gestão de resíduos e eficiência energética. Nos anos 1990 o destaque se deu por conta das políticas ambientais de âmbito global (Tauche; Brandli, 2006).

A percepção de que essas instituições são parte ativa do problema, ao possuírem campi com práticas de gestão não compatíveis com a preservação do meio ambiente, levou cerca de 30 Universidades a assinar em 1990 a Declaração de Talloires (1990), que concluiu que as IESs deveriam urgentemente prover a liderança e o suporte necessários para mobilizar fontes internas e externas para superar esse enorme desafio. A Declaração de Halifax (1991) salientava a responsabilidade das IESs em ajudar as sociedades no presente e no futuro, moldar políticas e ações de desenvolvimento em direção à sustentabilidade. Outras articulações entre as IESs começaram a surgir após a segunda Conferência sobre Meio Ambiente e Desenvolvimento realizada no Rio de Janeiro em 1992. Em 1993, em Kyoto (1993), 650 IESs explicitaram que a missão das Universidades seria estabelecer e disseminar uma concepção clara de desenvolvimento sustentável.

Em 1995, foi criada a Organização Internacional de Universidades pelo Desenvolvimento Sustentável e Meio Ambiente (Oiudsma); em 2000, a Global Higher Education for Sustainability Partnership (Guesp), Parceria Global do Ensino Superior para o Desenvolvimento Sustentável; e em 2002 foi realizada a primeira Environmental Management for Sustainable Universities (Emsu), Conferência Internacional sobre Gestão Ambiental para as Universidades Sustentáveis. Em 2005, a ONU criou a Década da Educação para o Desenvolvimento Sustentável. Em 2007, foi desenvolvida a iniciativa Principles for Responsible Management Education (PRME) sob coordenação do Pacto Global das Nações Unidas e instituições acadêmicas importantes mundialmente (Termignoni, 2012).

Atualmente, há alguns Simpósios, Encontros e Conferências que tratam da dimensão ambiental especificamente das IESs: (i) a Environmental Management for Sustainable Universities (Emsu); (ii) o Encontro Latino-Americano das Universidades Sustentáveis (Elaus); (iii) o Simpósio a Universidade frente aos Desafios da Sustentabilidade: Educação para a Sustentabilidade. Este último possui apoio institucional da Unesco e sua abrangência é regional. A Universidade Federal do Rio Grande do Sul (Ufrgs) e a Pontifícia Universidade Católica do Rio Grande do Sul (PUCRS) já sediaram o Simpósio (Termignoni, 2012).

A figura 1 apresenta um breve resumo do histórico dos eventos e relatórios relacionados ao desenvolvimento sustentável das IESs. 


\begin{tabular}{|c|c|}
\hline \multirow[t]{2}{*}{1990} & Declaraçäo de Talloires, França. \\
\hline & $\begin{array}{l}\text { Mais de } 400 \text { universidades de várias regiöes do mundo. } \\
\text { Secretariada pela Association of University Leaders for a Sustainable Future (ULSF) }\end{array}$ \\
\hline \multirow[t]{2}{*}{1991} & Declaraçăo de Halifax, Canadá \\
\hline & $\begin{array}{l}\text { Universidades ligadas à ONU, associaçäo das universidades do Canadá e } \\
\text { universidades de várias regióes do mundo }\end{array}$ \\
\hline \multirow[t]{2}{*}{1993} & Declaração de Swansea, Suécia \\
\hline & Associação das universidades comunitárias \\
\hline \multirow[t]{2}{*}{1993} & Declaraçăo de Kyoto, Japão \\
\hline & Universidades de várias regiöes do mundo \\
\hline \multirow[t]{2}{*}{1994} & Carta Copernicus, Carta Universitária para o Desenvolvimento Sustentável \\
\hline & Associação das universidades europeias \\
\hline \multirow[t]{2}{*}{$2000 / 02$} & Declaraçäo de Haga, Suécia \\
\hline & Ministros, autoridades e instituiç̃es educacionais da regiäo do Mar Báltico. \\
\hline 1995 & $\begin{array}{l}\text { Criação da Organização Internacional de Universidades pelo Desenvolvimento } \\
\text { Sustentável e Meio Ambiente (OlUDSMA), Säo José, Costa Rica } \\
20 \text { universidades da Europa e América do Norte, Central e do Sul }\end{array}$ \\
\hline 2000 & $\begin{array}{l}\text { Global Higher Education for Sustainability Partnership (GUESP). Parceria Global } \\
\text { do Ensino Superior para o Desenvolvimento Sustentável } \\
\text { ULSF/ Copemicus-campuol Intemational Association of Universities (IAU) UNESCO }\end{array}$ \\
\hline \multirow[t]{2}{*}{2001} & Declaraçäo de Luneburg \\
\hline & $\begin{array}{l}\text { Conferência sobre o Ensino Superior para o Desenvolvimento Sustentável } \\
\text { GHESP - Global Higher Education for Sustainability Partnership, em representaçäo de } \\
\text { mais de } 1.000 \text { universidades a nivel mundial }\end{array}$ \\
\hline \multirow[t]{2}{*}{2001} & Criação da Rede Universitária de Programas de Educação Ambiental (RUPEA) \\
\hline & Rede de universidades brasileiras \\
\hline 2002 & $\begin{array}{l}\text { Environmental Management for Sustainable Universities (EMSU), Conferências } \\
\text { Internacionais sobre Gestão Ambiental para as Universidades Sustentáveis, } \\
\text { África do Sul } \\
150 \text { delegados de todas as partes do mundo }\end{array}$ \\
\hline 2005 & $\begin{array}{l}\text { Criação da Association for the Advancement of Sustainability in Higher } \\
\text { Education (AASHE). Associação para o Avanço da Sustentabilidade no Ensino } \\
\text { Superior } \\
\text { Primeira associaçäo da América do Norte (EUA e Canadá) }\end{array}$ \\
\hline \multirow[t]{2}{*}{2006} & EcoCampus, Reino Unido \\
\hline & $\begin{array}{l}\text { The Environmental Association for Universities and Colleges (EAUC) do Reino Unido / } \\
\text { Environmental Campaigns (ENCAMS) }\end{array}$ \\
\hline \multirow[t]{2}{*}{2007} & Criação do People \& Planet Green League \\
\hline & Ranking de universidades do Reino Unido com base nas suas práticas sustentáveis \\
\hline \multirow[t]{2}{*}{2007} & PRME - Principles for Responsible Management Education \\
\hline & $\begin{array}{l}\text { Conjunto de seis princípios. Pacto Global das Nações Unidas e instituip̧öes } \\
\text { académicas importantes mundialmente. }\end{array}$ \\
\hline \multirow[t]{2}{*}{2009} & Criação da Alternative University Appraisal (AUA) \\
\hline & Comunidade das universidades asiáticas \\
\hline
\end{tabular}

Figura 1: Histórico dos eventos relacionados à preocupação ambiental em Universidades Fonte: Termignoni (2012)

Em todo o mundo há diversas IESs que possuem políticas ambientais na sua gestão. Contudo, poucas possuem certificação ISO 14001 (Delgado; Velez, 2005). Entre as normas de maior aceitação, destaca-se a Norma NBR ISO 14001 por sua crescente importância, e por fornecer ferramentas e estabelecer um padrão de sistema, que especifica as principais exigências para sua implantação e adoção, orientando a empresa na elaboração da política ambiental e no estabelecimento de estratégias, objetivos e metas, levando em consideração os impactos ambientais significativos e a legislação ambiental em vigor no país. É uma norma internacional de amplo aceite e aplicação em nível empresarial, de uso voluntário (ISO, 1996).

A Gestão Ambiental em Universidades deve incluir análises responsáveis e detalhadas de cada fluxo num campus, devendo ser baseada em unidades físicas, porém permitindo também que sejam consideradas questões econômicas; incluir a avaliação de indicadores consistentes; envolver estudos detalhados destes indicadores visando compreender e estimar o potencial de melhoria do sistema; e servir para a melhoria contínua dos parâmetros ambientais do sistema, de acordo com o comprometimento ambiental exemplar (Tauchen; Brandli, 2006). 


\subsection{Posturas e práticas de Gestão Ambiental em Universidades}

Existem duas correntes de pensamento principais referentes ao papel desempenhado pelas IESs no tocante ao desenvolvimento sustentável. A primeira, destaca a questão educacional como uma prática fundamental para que as IESs, pela formação, possam contribuir na qualificação de seus egressos, futuros tomadores de decisão, para que incluam em suas práticas profissionais a preocupação com as questões ambientais. A segunda corrente destaca a postura de algumas IESs na implementação de Sistemas de Gestão Ambiental - SGA em seus campi universitários, como modelos e exemplos práticos de gestão sustentável para a sociedade (Tauchen; Brandli, 2006).

De acordo com esta segunda corrente, existem razões significativas para implantar práticas ambientais nas IESs, pois estas podem ser comparadas a pequenos núcleos urbanos, já que o campus precisa de infraestrutura básica, redes de abastecimento de água e energia, redes de saneamento e coleta de águas pluviais e vias de acesso, como mostra a Figura 2. Além disto, envolvem diversas atividades de ensino, pesquisa, extensão e atividades referentes à sua operação por meio de bares, restaurantes, alojamentos, centros de conveniência, entre outros (Careto; Vendeirinho, 2003).

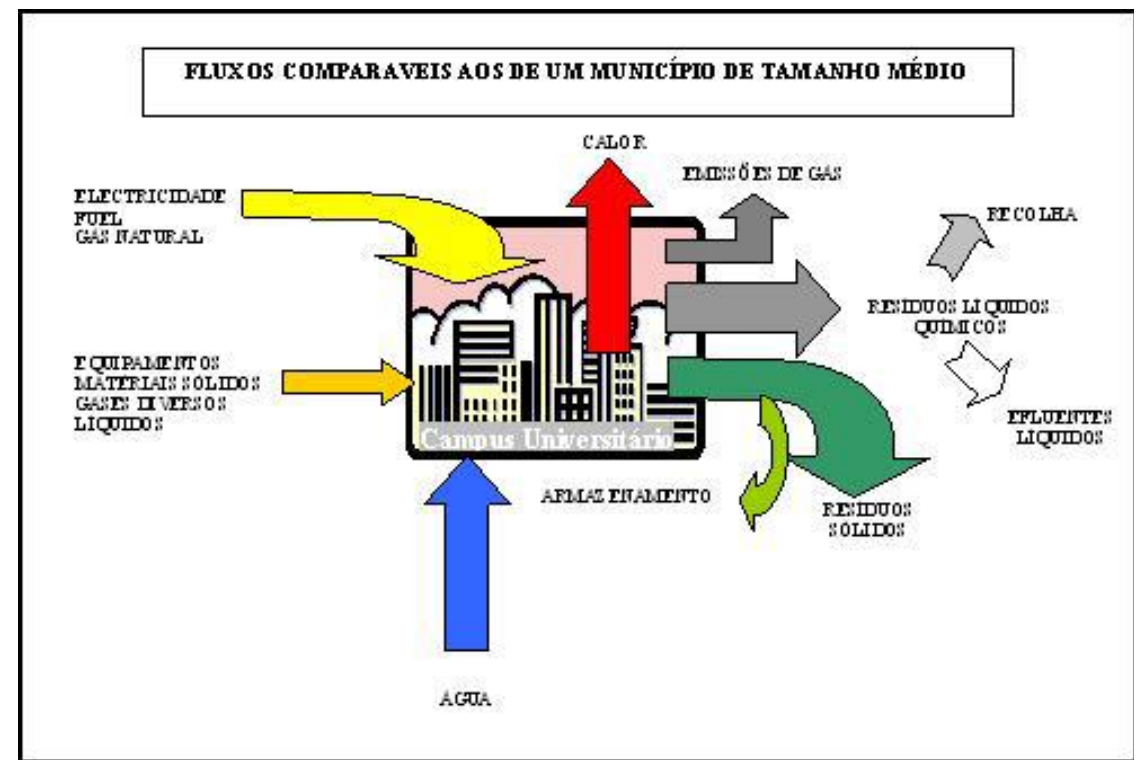

Figura 2: Principais fluxos de um campus universitário

Fonte: Careto e Vendeirinho

Como consequência de suas atividades e operações, há geração de resíduos sólidos e efluentes líquidos, consumo de recursos naturais, ou seja, a visão industrial de inputs e outputs. As Universidades geram significativos impactos ambientais, como a manutenção constante dos edifícios e espaços, uso de pesticidas e outros químicos, produção de resíduos perigosos, só para referir algumas das causas de possíveis impactos ambientais. Na essência, com um leque tão grande de impactos potenciais, uma Gestão Ambiental bem-sucedida de escolas e Universidades requer uma aproximação à Gestão Ambiental similar à que pode ser aplicada nas pequenas cidades, mas com especificidades próprias (Careto; Vendeirinho, 2003).

Os mesmos autores expõem que uma das vertentes da sustentabilidade nas instituições de ensino pode voltar-se à melhoria do seu desempenho ambiental, pois um sistema de Gestão Ambiental estabelecido numa organização pode reduzir, de forma significativa, a quantidade de materiais e energia requeridos para as atividades, resultando em significativas economias de custos e benefícios de desempenho ambiental. $\mathrm{Na}$ via da excelência ambiental, pode-se recorrer ao desenvolvimento e a aplicação de boas práticas ambientais, que apresentam diversas vantagens, tais como a redução de custos, a conformidade com a legislação vigente, a antecipação a futuras leis, redução do risco ambiental, melhoria da imagem perante os públicos internos e externos. 
Com base nas normas de implementação para Sistemas de Gestão Ambiental NBR ISO 14001 (ISO, 1996) e de pesquisas realizadas por Careto e Vendeirinho (2003), Tauchen e Brandli (2006) e Engelman, Guisso e Fracasso (2009) foram identificadas diversas práticas de Gestão Ambiental:

\begin{tabular}{|l|}
\hline Políticas de Gestão Ambiental \\
\hline Guia de boas práticas de ações ambientais/ sustentáveis \\
\hline Auditoria ambiental para indicar melhorias \\
\hline Utilização de indicadores ambientais \\
\hline Acompanhamento e análise da questão de sustentabilidade ambiental \\
\hline Diagnóstico dos impactos significativos para o ambiente \\
\hline Soluções baseadas no padrão ISO 14001 \\
\hline Departamento/área para Gestão Ambiental \\
\hline Construções e reformas na instituição seguindo padrões de sustentabilidade \\
\hline Cursos de formação de gestores ambientais \\
\hline Treinamento e sensibilização da equipe de funcionários \\
\hline Programas de conscientização ambiental voltado à população \\
\hline Programas de conscientizção ambiental voltado aos alunos \\
\hline Inclusão no currículo de conteúdos sobre sustentabilidade ambiental \\
\hline Desenvolvimento de projetos de pesquisa sobre sustentabilidade ambiental \\
\hline Disseminação dos projetos ambientais desenvolvidos dentro da instituição \\
\hline Parceria com outras Universidades para desenvolver a questão ambiental \\
\hline Organização de eventos sobre a questão ambiental \\
\hline Disponibilização de alimentação orgânica \\
\hline Controle de consumo e reuso de água \\
\hline Controle de consumo de energia \\
\hline Controle de efluentes \\
\hline Controle de resíduos \\
\hline Racionalização do uso de combustíveis \\
\hline Uso de combustíveis alternativos \\
\hline Utilização de material reciclado (papel) \\
\hline Programas de seleção do lixo \\
\hline Critérios ambientais para fornecedores de materiais de consumo \\
\hline Espaços verdes - controle da vegetação \\
\hline Plano de ação para melhoria contínua da sustentabilidade ambiental \\
\hline
\end{tabular}

Figura 3: Práticas de Gestão Ambiental em Universidades

Fonte: Engelman, Guisso e Fracasso (2009)

Contudo, as práticas e estruturas dos sistemas de Gestão Ambiental em IES podem variar dependendo da sua localização geográfica, dimensão, das condições do ambiente local, da capacidade de aproveitamento de oportunidades, cooperação interinstitucional, capacidade de concretização de parcerias com entidades muito diferentes e outros aspectos. Assim, as seções seguintes apresentam o método adotado no estudo e os resultados, visando compreender melhor estas práticas.

\section{MÉTODO}

Segundo Hair et al. (2005), a pesquisa descritiva é assim denominada, pois faz uso de estatísticas descritivas para caracterizar uma amostra ou população e técnicas multivariadas. Este tipo de pesquisa, também chamada de survey, possui caráter essencialmente quantitativo. Assim, caracteriza-se por dados apresentados em formas de tabela, cumprindo com o objetivo de generalizar os resultados da amostra para a população-alvo (Malhotra, 2001).

A população desta pesquisa é composta pelo total de 192 Universidades brasileiras (MEC, 2012) chegando-se a uma amostra probabilística aleatória simples de 75 Universidades, com uma margem de erro na representatividade da amostra de $9 \%$. 
De acordo com o Ministério da Educação e Cultura (MEC), por meio do decreto 2.306/97, as IESs são classificadas conforme sua organização acadêmica, sendo Universidades as instituições pluridisciplinares que oferecem atividades de ensino, pesquisa e extensão com regularidade (Mec, 2012). Entre as onze dimensões estabelecidas para garantir a unidade do processo avaliativo pelo Sistema Nacional de Avaliação da Educação Superior (Sinaes), está a responsabilidade social da instituição, que, segundo Silva (2009, p.42), é “[...]considerada especialmente no que se refere à sua contribuição em relação à inclusão social, ao desenvolvimento econômico e social, à defesa do meio ambiente, da memória cultural, da produção artística e do patrimônio cultural".

A figura 3 serviu de base para a elaboração do questionário de pesquisa. Também foram incluídos questionamentos sobre as características das instituições, e sobre as principais motivações e barreiras para a implementação das práticas de Gestão Ambiental. Os dados foram coletados pelos pesquisadores do Centro de Pesquisas em Administração (Cepa) da Universidade Federal do Rio Grande do Sul (UFRGS), por meio de contato telefônico com abordagem aleatória, com os gestores responsáveis pela Gestão Ambiental das instituições. Nenhum questionário precisou ser descartado.

A apresentação dos resultados contemplou análise descritiva das variáveis, com os dados de frequência. Segundo Malhotra (2001), a distribuição de frequência tem como objetivo obter uma contagem do número de respostas associadas a diferentes valores da variável, o que permite obter informações básicas, que podem ser resumidas com o auxílio de estatísticas descritivas. Também foi utilizado um conjunto de testes estatísticos para verificar a relação existente entre as variáveis, a partir dos testes de cruzamento, e das diferenças de percepções entre os respondentes da amostra, utilizando testes de comparação de média - Anova. A margem de erro considerada foi de 5\%.

\section{APRESENTAÇÃO E ANÁLISE DOS DADOS}

O perfil da amostra demonstra que $29,3 \%$ das Universidades estão localizadas na região sudeste; $26,7 \%$, na região centro-oeste; $21,3 \%$, na região sul; $12 \%$, na região norte; e $10,7 \%$ na região nordeste. Em relação à categoria administrativa das instituições, $48 \%$ das Universidades são privadas; $32 \%$, públicas; e $20 \%$ de outra natureza. Em relação ao tamanho, $22,7 \%$ têm até 5000 alunos; $21,4 \%$, de 5001 a 10 mil alunos; $26,7 \%$, de 10.001 a 20 mil alunos; $13,4 \%$, de 20.001 a 30 mil e $16 \%$ não opinaram.

Entre as principais motivações para implementar práticas de Gestão Ambiental nas Universidades, conforme a Figura 4, os entrevistados apontaram a preocupação com o meio ambiente, e conscientizar a sociedade através de projetos de educação em que esteja servindo como exemplo. Estas duas maiores motivações também foram identificadas nos estudos de Ribeiro et al. (2005) e Engelman, Guisso e Fracasso (2009). Contudo, é preocupante que $14 \%$ dos gestores responsáveis pela Gestão Ambiental das instituições não saiba o que as motiva. Esta fragilidade pode impactar na adoção de práticas ambientais pelas Universidades.

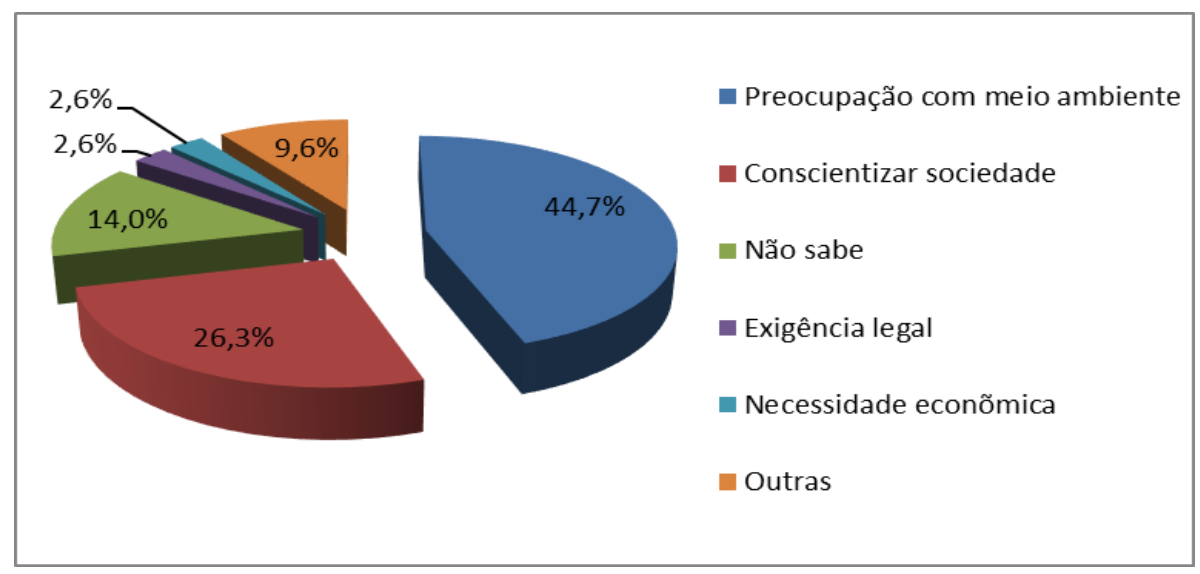

Figura 4: Motivações para práticas de Gestão Ambiental em universidades brasileiras

Fonte: Os autores

Revista de Gestão Social e Ambiental - RGSA, São Paulo, v. 7, n. 3, p. 37-51, out./dez., 2013. 
De acordo com a Figura 5, as principais barreiras para implementar práticas de Gestão Ambiental nas Universidades estão relacionadas com a falta de recursos, principalmente humanos e financeiros, dificuldade de conscientização dos envolvidos e falta de interesse das próprias instituições de ensino. A falta de conscientização e interesse também foram destacados por Ribeiro et al. (2005) e Engelman, Guisso e Fracasso (2009). Entretanto, a falta de recursos, identificada como principal barreira nesta pesquisa, não havia sido mencionada anteriormente. Este resultado pode sinalizar que a conscientização dos envolvidos tenha aumentado, como reflexo do aumento de consciência da sociedade em relação aos cuidados com o meio ambiente. Contudo, é fundamental que haja maior incentivo e investimento por parte de governo e das próprias instituições de ensino.

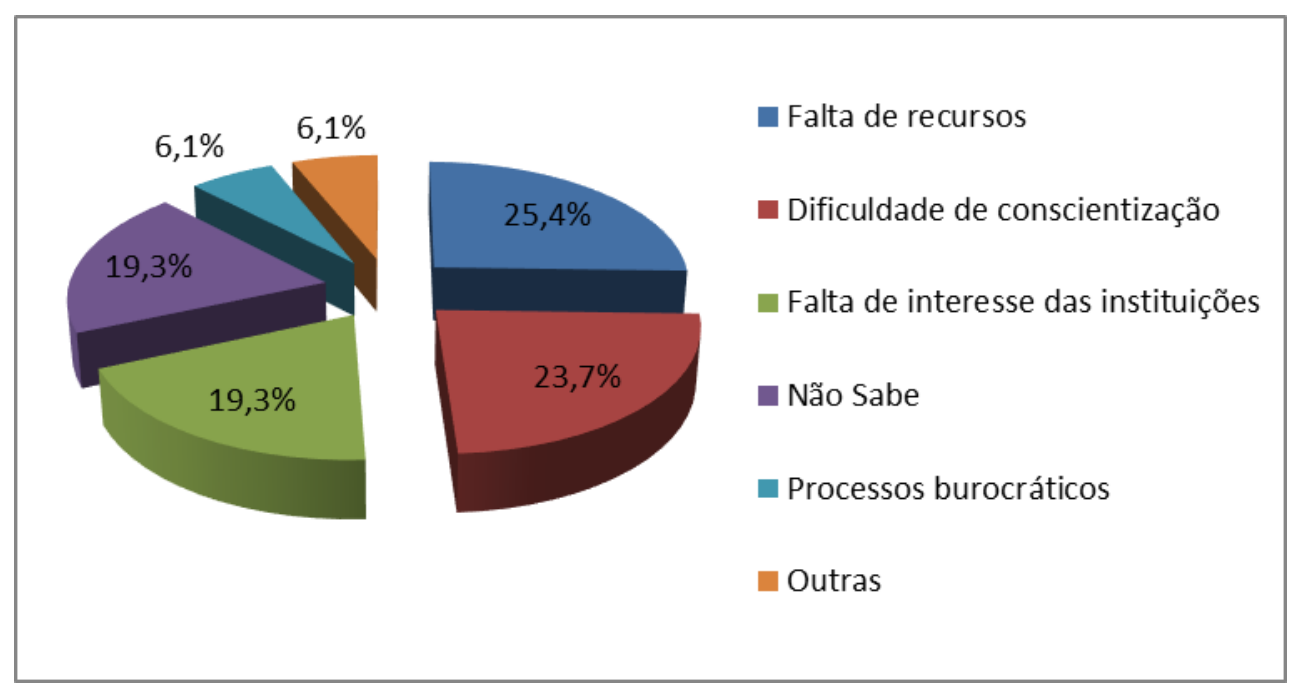

Figura 5: Barreiras para práticas de gestão ambiental em universidades brasileiras

Fonte: Os autores

Como é possível verificar na Tabela 1, que contém percentual de média e desvio- padrão calculados com base nas respostas das universidades pesquisadas, grande parte das 29 práticas de Gestão Ambiental tem sido adotada pelas instituições de ensino superior. Quando se analisa o nível de adoção dessas práticas por parte das Universidades, percebe-se desde poucas instituições que não adotam nenhuma prática, a maioria das instituições adotando muitas práticas, até outro extremo com poucas instituições de ensino com alto nível de adoção de práticas de gestão ambiental em seus campi.

Tabela 1: Práticas de gestão ambiental em universidades brasileiras

\begin{tabular}{l|c|c}
\multicolumn{1}{c}{$\begin{array}{c}\text { Práticas } \\
\text { Políticas de Gestão Ambiental }\end{array}$} & $\begin{array}{c}\text { Média } \\
\text { Pesvio } \\
\text { Padrão }\end{array}$ \\
\hline Guia de boas práticas de ações ambientais/ sustentáveis & 3,51 & 1,143 \\
\hline Auditoria ambiental para indicar melhorias & 3,32 & 1,286 \\
\hline Utilização de indicadores ambientais & 3,05 & 1,423 \\
\hline Acompanhamento e análise da questão de sustentabilidade ambiental & 3,15 & 1,353 \\
\hline Diagnóstico dos impactos significativos para o ambiente & 3,28 & 1,361 \\
\hline Soluções baseadas no padrão ISO 14001 & 3,35 & 1,457 \\
\hline Criação de um departamento para Gestão Ambiental & 1,64 & 1,123 \\
\hline Construções e reformas na instituição seguindo padrões de sustentabilidade & 2,81 & 1,363 \\
\hline Cursos de formação de gestores ambientais & 3,35 & 1,330 \\
\hline Treinamento e sensibilização da equipe de funcionários & 3,43 & 1,367 \\
\hline Programas de conscientização ambiental voltados à população & 3,75 & 1,264 \\
\hline Programas de conscientização ambiental voltados aos alunos & 3,96 & 1,191 \\
\hline
\end{tabular}




\begin{tabular}{l|c|c} 
Inclusão no currículo de conteúdos sobre sustentabilidade ambiental & 3,84 & 1,220 \\
\hline Desenvolvimento de projetos de pesquisa sobre sustentabilidade ambiental & 3,63 & 1,271 \\
\hline Disseminação dos projetos ambientais desenvolvidos dentro da instituição & 3,61 & 1,229 \\
\hline Parceria com outras Universidades para desenvolver a questão ambiental & 3,04 & 1,537 \\
\hline Organização de eventos sobre a questão ambiental & 3,60 & 1,252 \\
\hline Disponibilização de alimentação orgânica & 2,52 & 1,455 \\
\hline Controle de consumo e reuso de água & 2,84 & 1,336 \\
\hline Controle de consumo de energia & 3,21 & 1,407 \\
\hline Controle de efluentes & 2,87 & 1,571 \\
\hline Racionalização do uso de combustíveis & 2,69 & 1,442 \\
\hline Uso de combustíveis alternativos & 2,87 & 1,536 \\
\hline Utilização de material reciclado & 3,65 & 1,289 \\
\hline Programas de reciclagem & 3,91 & 1,275 \\
\hline Critérios ambientais para fornecedores de materiais de consumo & 3,25 & 1,443 \\
\hline Espaços verdes - controle da vegetação & 3,48 & 1,418 \\
\hline Plano de ação para melhoria contínua da sustentabilidade ambiental & 3,32 & 1,416 \\
\hline
\end{tabular}

Fonte: Os autores

São 13 práticas que apresentaram maior nível de adoção por parte das Universidades: políticas de Gestão Ambiental; diagnóstico dos impactos significativos para o ambiente; treinamento e sensibilização da equipe de funcionários; programas de conscientização ambiental voltados à população; programas de conscientização ambiental voltados aos alunos; inclusão no currículo de conteúdos sobre sustentabilidade ambiental; desenvolvimento de projetos de pesquisa sobre sustentabilidade ambiental; disseminação dos projetos ambientais desenvolvidos dentro da instituição; organização de eventos sobre a questão ambiental; utilização de material reciclado; programas de reciclagem; espaços verdes - controle da vegetação; plano de ação para melhoria contínua da sustentabilidade ambiental.

Pode-se observar que grande parte destas ações está voltada para aumentar a conscientização sobre os cuidados com o meio ambiente, especialmente dos públicos diretamente envolvidos com a Universidade, apontados como principal motivação e também barreira para a implantação de práticas de Gestão Ambiental pelos gestores. Também é possível inferir que estas ações requerem menor investimento financeiro e qualificação de pessoal que as demais, mostrando que as instituições, apesar da falta de recursos, estão buscando alternativas viáveis para as ações ambientais.

Estes dados estão de acordo com Boyle (1999), quando afirma que a política ambiental das instituições deve envolver aspectos ambientais a serem incorporados em todos os setores, desde a criação de novos cursos até a publicação de artigos, o que propõe que esforços no campo ambiental devam enfatizar a tentativa de aproximar a universidade da comunidade e em envolver os colaboradores. Contudo, o autor afirma que muitas vezes a pesquisa é ressaltada em detrimento do ensino, e os resultados em relação às práticas de Gestão Ambiental mostraram o contrário.

Outras nove práticas apresentaram nível intermediário de adoção pelas Universidades: guia de boas práticas de ações ambientais/sustentáveis; auditoria ambiental para indicar melhorias; utilização de indicadores ambientais; acompanhamento e análise da questão de sustentabilidade ambiental; construções e reformas na instituição seguindo padrões de sustentabilidade; cursos de formação de gestores ambientais; parceria com outras Universidades para desenvolver questões relacionadas à Gestão Ambiental; controle de consumo de energia; critérios ambientais para fornecedores de materiais de consumo. É possível inferir que estas ações necessitam de maior investimento financeiro e de recursos humanos com maior capacitação técnica.

Sete práticas apresentaram os níveis mais baixos de adoção pelas Universidades: soluções baseadas no padrão ISO 14001; criação de um departamento para Gestão Ambiental; disponibilização de alimentação orgânica; controle de consumo e reuso de água; controle de efluentes; racionalização do uso de combustíveis e uso de combustíveis alternativos. Estas ações

Revista de Gestão Social e Ambiental - RGSA, São Paulo, v. 7, n. 3, p. 37-51, out./dez., 2013. 
necessitam ainda maior comprometimento e investimento por parte das Universidades, pois são mais complexas de gerenciar.

Ao contrário deste resultado, Tauchen e Brandli (2006), em sua pesquisa bibliográfica de 42 casos de Universidades estrangeiras, identificaram como prática mais presente o controle e reuso da água. É provável que esta diferença esteja relacionada com a disponibilidade deste recurso no Brasil e com questões culturais.

Entre as Universidades pesquisadas, 25,3\% têm Sistema de Gestão Ambiental (SGA) implantado; $20 \%$ está em fase de implantação e 54,7\% não possuem sistema, ou seja, 45,3\% estão voltadas ao desenvolvimento de SGA (Figura 6). Somente três Universidades possuem certificação ISO 14001. Engelman, Guisso e Fracasso (2009) e Termignoni (2012) salientam em suas pesquisas que instituições com certificação apresentavam mais práticas e relatórios de Gestão Ambiental mais completos, o que ocorre devido às exigências para atingir os padrões exigidos para a certificação. Contudo, grande parte das instituições deste estudo não demonstra interesse na ISO 14001, o que pode influenciar negativamente a adoção de algumas práticas ambientalmente responsáveis.

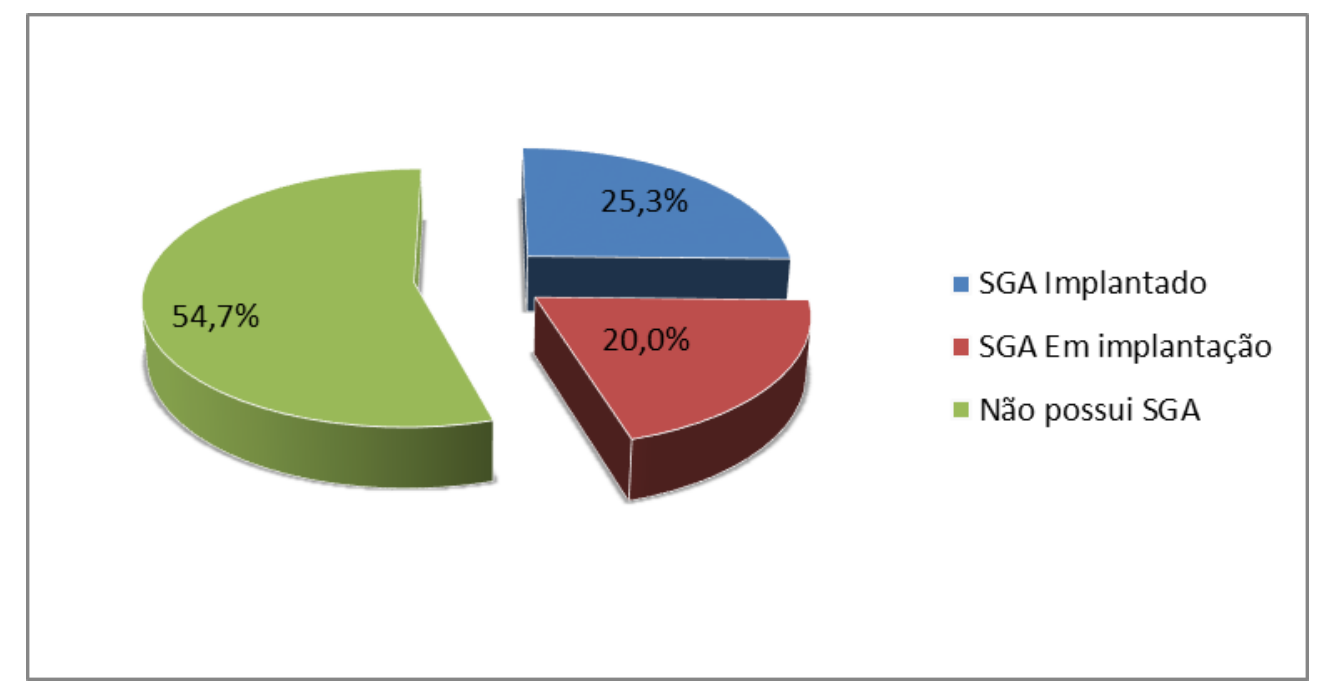

Figura 6: Sistemas de gestão ambiental em universidades brasileiras Fonte: Os autores

Com base no teste de comparação de média - Anova - realizado com as práticas de Gestão Ambiental, verifica-se que existe diferença estatística significativa entre as instituições que possuem SGA implantado, em fase de implantação ou não possuem. Na Tabela 2 é possível observar as práticas que obtiveram grau de significância menor ou próximo a 5\%. O grupo que manifestou maior média em todas estas práticas foram as Universidades que possuem SGA já implantado. Além disso, é possível observar que estas ações especificamente necessitam de um programa de Gestão Ambiental mais desenvolvido e que são também mais formalizadas, sendo, portanto, compatíveis com as que já tem sistema implantado.

Tabela 2: Relação entre as práticas e sistema de gestão ambiental

\begin{tabular}{l|c|c|c|c}
\multicolumn{1}{c}{ Ações } & Implantado & Implantação & Não possui & Sig. \\
\hline Políticas de Gestão Ambiental & 4,1 & 3,2 & 3,3 &, 026 \\
\hline Auditoria ambiental para indicar melhorias & 3,8 & 2,6 & 2,9 &, 025 \\
\hline Soluções baseadas no padrão ISO 14001 & 2,3 & 1,3 & 1,5 &, 007 \\
\hline Criação de um departamento para Gestão Ambiental & 4,0 & 2,7 & 2,3 &, 000 \\
\hline Cursos de formação de gestores ambientais & 4,0 & 2,9 & 3,4 &, 049 \\
\hline Controle de consumo e reuso de água & 3,5 & 2,5 & 2,6 &, 031 \\
\hline
\end{tabular}

Fonte: Os autores 
Como resultado das entrevistas, identificou-se que $40 \%$ das Universidades possui departamento específico para a Gestão Ambiental da instituição, e nas demais $60 \%$ que não possuem departamento (Figura 7), as ações são gerenciadas por cursos e grupos de pesquisas que estudam o meio ambiente (14,7\%), departamentos administrativos das instituições (12\%), departamentos de engenharia civil $(6,7 \%)$, outros departamentos $(6,7 \%)$ e $20 \%$ não tem nenhum departamento responsável pelas práticas.

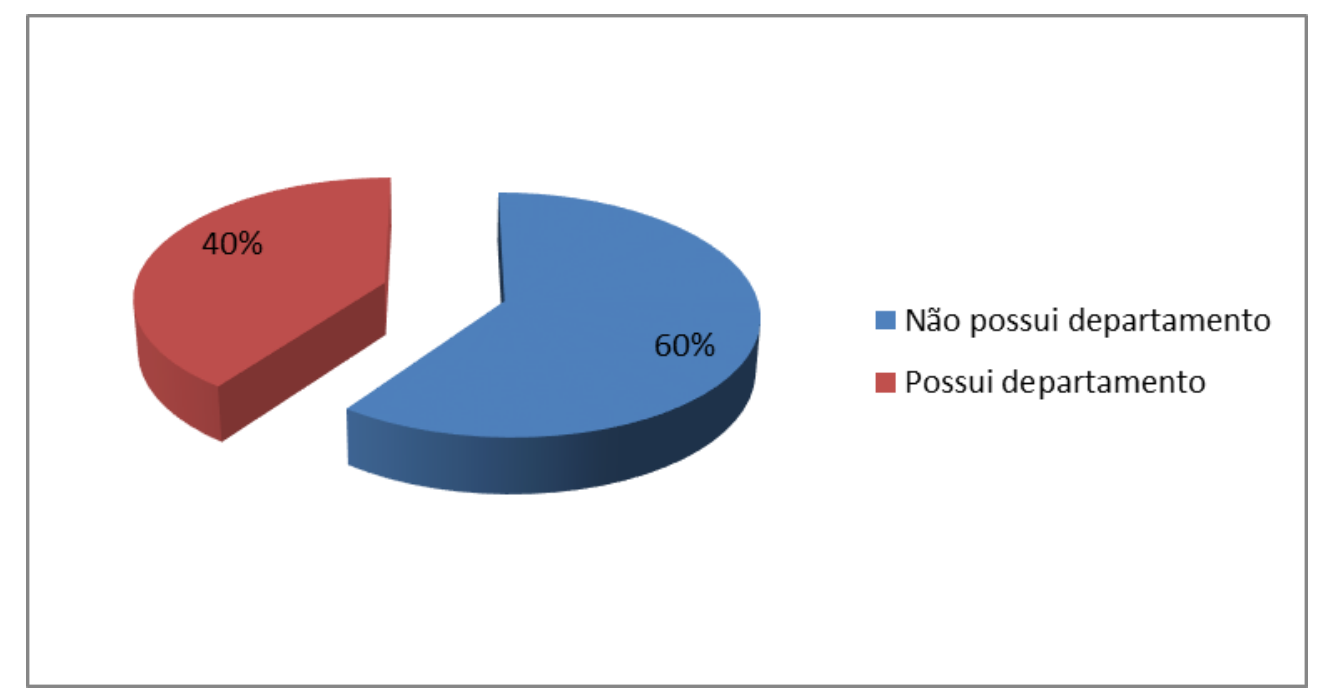

Figura 7: Departamento de gestão ambiental em universidades brasileiras

Fonte: Os autores

Comparando, a partir do teste de diferença de média - Anova, as instituições que possuem departamento específico para a Gestão Ambiental e as que não possuem, verifica-se que existe diferença no nível de adoção de práticas de Gestão Ambiental. Na Tabela 3, é possível observar as práticas que obtiveram grau de significância menor ou próximo a $5 \%$. O grupo que manifestou maior média em todas estas práticas foram as Universidades que possuem departamentos específicos. Portanto, é possível notar que nas instituições que possuem um departamento a quantidade de práticas adotadas é maior, além disso, entre estas ações estão as que necessitam de maior investimento e recursos humanos qualificados.

Tabela 3: Relação entre as práticas e Departamento de Gestão Ambiental

\begin{tabular}{|c|c|c|c|}
\hline Práticas & Não possui & Possui & Sig. \\
\hline Guia de boas práticas de ações ambientais/ sustentáveis & 3,1 & 3,7 & ,036 \\
\hline Auditoria ambiental para indicar melhorias & 2,8 & 3,4 & 058 \\
\hline Diagnóstico dos impactos significativos para o ambiente & 3,1 & 3,7 & ,060 \\
\hline Soluções baseadas no padrão ISO 14001 & 1,4 & 2,0 & ,012 \\
\hline Criação de um departamento para Gestão Ambiental & 2,6 & 3,2 & ,044 \\
\hline Construções e reformas na instituição seguindo padrões de sustentabilidade & 3,1 & 3,7 & ,060 \\
\hline Programas de conscientização ambiental voltados à população & 3,7 & 4,4 & ,008 \\
\hline Programas de conscientização ambiental voltados aos alunos & 3,9 & 4,5 & ,036 \\
\hline Desenvolvimento de projetos de pesquisa sobre sustentabilidade ambiental & 3,4 & 4,0 & ,023 \\
\hline Disseminação dos projetos ambientais desenvolvidos dentro da instituição & 3,3 & 4,1 & ,008 \\
\hline Controle de consumo e reuso de água & 2,5 & 3,3 & ,008 \\
\hline Controle de consumo de energia & 2,9 & 3,7 & ,022 \\
\hline Racionalização do uso de combustíveis & 2,4 & 3,2 & ,019 \\
\hline Utilização de material reciclado & 3,4 & 4,0 & ,036 \\
\hline Critérios ambientais para fornecedores de materiais de consumo & 2,9 & 3,8 & ,004 \\
\hline Plano de ação para melhoria contínua da sustentabilidade ambiental & 3,1 & 3,7 & 057 \\
\hline
\end{tabular}

Fonte: Os autores 
Com base no teste de comparação de média - Anova - verifica-se que existe diferença no nível de adoção de práticas de Gestão Ambiental que as Universidades têm praticado em relação à localização das instituições.

Em relação à inclusão no currículo de conteúdos sobre sustentabilidade ambiental, as instituições localizadas no norte apresentaram maior média $(4,3)$; seguidas pelas localizadas no Sudeste $(4,2)$; localizadas no Sul $(4,0)$; localizadas no centro-oeste $(3,6)$ e nordeste $(2,8)$.

Em relação ao desenvolvimento de projetos de pesquisa sobre sustentabilidade ambiental, as instituições localizadas no Sudeste apresentaram maior média $(4,1)$; seguidas pelas localizadas no Norte $(3,8)$; localizadas no Sul $(3,7)$; localizadas no Centro-Oeste $(3,4)$ e Nordeste $(2,5)$.

Em relação à disseminação dos projetos ambientais desenvolvidos dentro da instituição, as instituições localizadas no Norte apresentaram maior média $(4,3)$; seguidas pelas localizadas no Sudeste $(4,0)$; localizadas no Sul $(3,6)$; localizadas no Centro-Oeste $(3,4)$ e nordeste $(2,4)$.

Com base nestes dados, é possível concluir que as instituições localizadas no Norte e Sudeste têm alto nível de adoção de práticas de Gestão Ambiental, enquanto instituições do Sul do país têm nível de adoção intermediário, e as instituições do Nordeste e Centro-Oeste apresentam os níveis mais baixos.

No mesmo sentido, o teste de comparação de média - Anova - possibilita identificar diferença no nível de adoção de práticas de Gestão Ambiental em relação ao tamanho da instituição. As instituições com mais de 20 mil alunos manifestaram maior média em soluções baseadas no padrão ISO 14001, criação de um departamento para Gestão Ambiental, construções e reformas na instituição seguindo padrões de sustentabilidade e controle de consumo de energia. É provável que estas instituições, por serem maiores, possuam maior infraestrutura e recursos para investir neste tipo de ação. Já as instituições que possuem entre 5 mil e 20 mil alunos manifestaram maior média em organização de eventos sobre a questão ambiental e uso de combustíveis alternativos, indicando que instituições com menos recursos procuram formas mais econômicas de investir em Gestão Ambiental.

Também verifica-se a diferença no nível de adoção de algumas práticas em relação a categoria administrativa da instituição. Nas quatro práticas - soluções baseadas no padrão ISO 14001, controle de consumo e reuso de água, controle de consumo de energia; racionalização do uso de combustíveis. O grupo que manifestou maior média foi o de Universidades privadas. É provável que as instituições privadas, visando maiores resultados financeiros, tenham maior preocupação com a economia de recursos e redução dos custos. As demais práticas não apresentaram diferença significativa de média entre as instituições públicas e privadas com a aplicação do teste de comparação de médias - Anova.

\section{CONSIDERAÇÕES FINAIS}

A importância das questões ambientais e sociais têm se salientado nas últimas décadas, demonstrando que o desenvolvimento sustentável é uma alternativa não só desejável, mas viável. Neste sentido, as Universidades são organizações que devem, além de cumprir o papel de educação e pesquisa, servir de exemplo a partir de suas práticas de Gestão Ambiental, minimizando seus impactos, ao mesmo tempo em que contribuem com a conscientização da sociedade.

Conforme já colocado em várias partes do mundo, principalmente nos países desenvolvidos, as ações das IESs em relação à sustentabilidade estão crescendo. No Brasil, encontram-se alguns estudos de casos sobre a Gestão Ambiental nestas instituições, mas é importante traçar um panorama nacional dessas políticas e ações. Neste sentido, este trabalho tinha como objetivo identificar as práticas de Gestão Ambiental realizadas nas universidades brasileiras a partir de uma survey.

Para atender ao objetivo da pesquisa, pela bibliografia foram identificadas as principais práticas desenvolvidas pelas organizações, e que serviram como base para o desenvolvimento do instrumento de coleta de dados. Também foram incluídas questões sobre as características das

Revista de Gestão Social e Ambiental - RGSA, São Paulo, v. 7, n. 3, p. 37-51, out./dez., 2013. 
instituições e sobre as principais motivações e barreiras para a implementação dessas ações. A coleta de dados foi realizada com uma amostra de 75 Universidades brasileiras.

Em síntese, o estudo evidenciou que grande parte das 29 práticas são realizadas pelas Universidades. Destas ações, 13 obtiveram alto nível de adoção e 9, nível moderado de adoção, somando 22 práticas de Gestão Ambiental implementadas em parte considerável das instituições de ensino superior. As práticas com alto nível de adoção são as que requerem menor investimento em infraestrutura física e de pessoal, estando também mais relacionadas com as competências principais das IESs. Já as ações com médio grau de adoção necessitam de maior investimento financeiro e de recursos humanos com maior capacitação técnica. As sete práticas que apresentaram os graus mais baixos de adoção necessitam de maior comprometimento e investimento por parte das Universidades, pois são mais complexas de serem implementadas e de gerenciar.

Os resultados gerais da pesquisa são compatíveis com a maior parte dos estudos de casos realizados no Brasil. Contudo, se diferem um pouco das pesquisas com Universidades estrangeiras. É possível que esta diferença esteja relacionada com a disponibilidade de recursos naturais e com questões culturais.

As principais motivações identificadas na implementação de práticas de Gestão Ambiental nas Universidades estão relacionadas com a preocupação com o meio ambiente e em conscientizar a sociedade por meio de projetos de educação/servindo como exemplo. Este resultado demonstra que, apesar das dificuldades, as instituições brasileiras estão voltadas para cumprir com sua responsabilidade ambiental e, por consequência, social. Em relação às principais barreiras foram apontados a falta de recursos, principalmente humanos e financeiros, a dificuldade de conscientização dos envolvidos e falta de interesse das próprias instituições de ensino.

Neste sentido, é importante que Universidades organizem programas internos de conscientização dos seus servidores, e que as políticas ambientais sejam prioridade para a gestão das instituições, fazendo parte de seu planejamento estratégico. Salienta-se que algumas práticas de Gestão Ambiental podem também contribuir para a diminuição dos custos financeiros, visto que pode-se economizar recursos. Ficou claro que as instituições que priorizam a Gestão Ambiental, implantando SGA e mantendo um departamento específico para a sua gestão, apresentam um nível de adoção de práticas mais elevado.

Em relação aos recursos, é importante contar com maior apoio governamental para este fim, levando em consideração as diferenças identificadas no estudo, como tamanho da instituição, localização e categoria administrativa. No entanto, é também fundamental que o investimento em Gestão Ambiental faça parte da previsão orçamentária das instituições e seja uma prioridade. Ainda, alternativas como parcerias com outras instituições devem ser buscadas.

Estes resultados contribuem para a formação de um panorama atual sobre as práticas de Gestão Ambiental desenvolvidas nas Universidades brasileiras. Também servem para auxiliar o planejamento de políticas públicas e para os gestores das instituições de ensino. Com relação às universidades, os resultados podem ser generalizados, uma vez que a amostra pesquisada (75 universidades correspondem a 39,06\% da população) é representativa. Porém, este estudo não considerou o perfil das instituições com relação aos tipos de atividades desenvolvidas, quantidade e tipos de laboratórios e práticas existentes, que podem interferir na adoção de determinadas práticas, sendo esta uma limitação do estudo. Recomenda-se ainda que estudos semelhantes sejam ampliados para outras Instituições de Ensino Superior, como faculdades e centros universitários, que somam quase 2.500 instituições no país.

\section{REFERÊNCIAS}

Associação Brasileira de Normas Técnicas. NBR ISO 14001 (1996) Diretrizes gerais sobre princípios, sistemas e técnicas de apoio. Rio de Janeiro: ABNT.

Boyle, C. (1999) Education, sustainability and cleaner production. Journal of Cleaner Production, 7(1), 83-87. 
Careto, H.; Vendeirinho, R. (2003) Sistemas de Gestão Ambiental em Universidades: Caso do Instituto Superior Técnico de Portugal. Relatório Final de Curso, Instituto Superior Técnico de Portugal. Recuperado em: 1 de julho de 2008, de: http://meteo.ist.utl.pt.

Delgado, C. C. J. \& Vélez, C. Q. (2005) Sistema de Gestión Ambiental Universitária: Caso Politécnico Gran Colombiano. Recuperado em: 1 de julho de 2008 de: http://ecnam.udistrital.edu.co/pdf/r/edge02/node03.pdf.

Donaire, D. (1999) Gestão ambiental na empresa (2a edição). São Paulo: Editora Atlas.

Engelman, R., Guisso, R., Fracasso, E. M. (2009) Ações de gestão ambiental nas instituições de ensino superior: o que tem sido feito. RGSA - Revista de Gestão Social e Ambiental, 3(1), 22-33.

Fouto, A. (2002) O papel das Universidades rumo ao desenvolvimento sustentável: das relações internacionais às práticas locais. Mestrado em Gestão e Políticas Ambientais, Relações Internacionais do Ambiente, 2002. Recuperado em: 1 de julho de 2008 de: http://campus.fct.unl.pt/campusverde/W_RIA_ARFF.doc.

Hair, J.F., Anderson, R. E., Tatham, RL., Black, W. (2005) Análise multivariada de dados (5a. edição) Porto Alegre: Bookman.

Kraemer, M. E. P. (2004) A universidade do século XXI rumo ao desenvolvimento sustentável. Revista Eletrônica de Ciência Administrativa, 3(2), 1-21.

Maimon, D. (1999) ISO 14001 - Passo a passo da implantação nas Pequenas e Médias Empresas. Rio de Janeiro: Qualitymark Editora Ltda.

Malhotra, N. (2001) Pesquisa de marketing: uma orientação aplicada (3a. Edição). Porto Alegre: Bookman.

MEC. (2012) Ministério da Educação e Cultura. Recuperado em: 15 de maio de 2012, de: http://emec.mec.gov.br/.

Ribeiro, A. L. et al. (2005) Avaliação de barreiras para implementação de um sistema de gestão ambiental na UFRGS. In: Encontro Nacional de Engenharia de Produção, 25, Porto Alegre, RS.

Salgado, M. M. A. (2006) Desenvolvimento de programa de gestão ambiental para Instituições de Ensino Superior. Estudo de caso: Instituto Esperança de Ensino Superior. Mestrado em Sistemas de Gestão, UFF - Niterói.

Silva, R. (2009) Balanced Scorecard-BSC Gestão do ensino superior. Gestão profissionalizada e qualidade de ensino para instituições de ensino superior privado. Curitiba: Juruá.

Tauchen, J., Brandli, L. A. (2006) Gestão ambiental em Instituições de Ensino Superior: modelo para implantação em campus universitário. Gestão e Produção, 13(3), 503-515.

Termignoni, L. D. (2012) Framework de sustentabilidade para Instituições de Ensino Superior Comunitárias. Dissertação de Mestrado em Administração. Pontifícia Universidade Católica do Rio Grande do Sul, Porto Alegre. 
The Halifax Declaration (1991) Recuperado em: 1 de julho de 2008 de: http://www.iisd.org/educate/declare.htm.

The Kyoto Declaration (1993) Recuperado em: 1 de julho de 2008 de: http://www.iisd.org/educate/declare.htm.

The Talloires Declaration (1990) Recuperado em: 1 de julho de 2008 de: http://www.iisd.org/educate/declare.htm.

Tilbury, D. (2012) Educación Superior para el Desarrollo Sostenible: Progresso? Perspectivas Globales. Recuperado em: 1 de julho de 2008 de:

http://www.projetosustentabilidade.sc.usp.br/index.php/Seminario-Internacional-de-Sostenibilidaden-la-Universidad/Apresentacoes-dos-Palestrantes-dias-17-e-18/17-nov-Palestras

Data da submissão: 29/07/2013

Data da publicação: 09/12/2013

Revista de Gestão Social e Ambiental - RGSA, São Paulo, v. 7, n. 3, p. 37-51, out./dez., 2013. 